\title{
Peak flow measurements among visitors to a public health exhibition
}

\author{
A. G. F. BROOKS and R. E. WALLER \\ MRC Air Pollution Unit, St. Bartholomew's Hospital Medical College, London EC1M 6BQ
}

\begin{abstract}
The results of measurements of peak flow made on 2,891 office workers and others attending a public health exhibition in the City of London have been analysed. After standardizing for height, peak flow was found to increase with age into the third decade before declining again, and there was evidence of a more rapid decline among continuing smokers than among those who had never smoked or had given up. Possible effects of exposure to air pollution were considered in terms of residential histories: mean peak flows for subjects born in London were a little below those of subjects born elsewhere.
\end{abstract}

An invitation to demonstrate some aspects of the work of the MRC Air Pollution Unit at a public health exhibition held in the City of London in April 1970 presented an opportunity to make simple measurements of ventilatory capacity on a large number of people and to examine the results in relation to smoking habits and exposure to air pollution. The Wright peak flow meter (Wright and McKerrow, 1959) was chosen for its portability and ease of operation. It was anticipated that the exhibition would be visited mainly by lunchtime crowds from nearby office blocks, and arrangements were made to staff a demonstration stand there from 12 noon to 2 p.m. each working day for the five weeks of the exhibition. To increase the number of teenagers in the sample, the survey was continued in further lunchtime sessions at a nearby college of further education attended by young workers on day release. In all, 2,891 people were seen (2,169 males and 722 females).

\section{METHODS}

The subjects were asked when and where they were born, where they lived, and details of their smoking habits. They were then weighed and their heights were measured. Finally, another member of the team showed them how to use the peak flow meter and recorded five measurements with it, the first two being regarded as trials. To deal with a rapid succession of subjects, several meters were used, but all were standardized regularly in our laboratory.

The peak flow records were examined for any evidence of observer bias: the results for each subject were calculated as a percentage of the value expected from the internal data of this study, and the mean 'PEF expected' was determined for each of the nine observers who had taken part. All the means were within $\pm 2 \%$ of the whole sample value of $100 \%$, and for all practical purposes the differences between observers were small and of no consequence.

\section{RESULTS}

VARIATIONS WITH HEIGHT, AGE, AND WEIGHT For the main analyses, the means of the last three peak flow readings were used, as recommended for survey work (Medical Research Council, 1966), but the five successive values were also examined separately (Table I). As expected, the mean of the

\section{TABLE I}

MEANS AND STANDARD DEVIATIONS FOR SUCCESSIVE PEAK FLOW MEASUREMENTS IN EACH SET OF 5

\begin{tabular}{|c|c|c|c|c|}
\hline \multirow{3}{*}{$\begin{array}{c}\text { Order } \\
\text { of PEF } \\
\text { Measurement }\end{array}$} & \multicolumn{4}{|c|}{ PEF (1/min) } \\
\hline & \multicolumn{2}{|c|}{ Males } & \multicolumn{2}{|c|}{ Females } \\
\hline & Mean & S.D. & Mean & S.D. \\
\hline $\begin{array}{l}\text { First } \\
\text { Second } \\
\text { Third } \\
\text { Fourth } \\
\text { Fifth }\end{array}$ & $\begin{array}{l}506 \cdot 5 \\
533 \cdot 5 \\
540 \cdot 7 \\
543 \cdot 9 \\
547 \cdot 6\end{array}$ & $\begin{array}{l}95 \cdot 7 \\
87 \cdot 1 \\
87 \cdot 4 \\
87 \cdot 0 \\
86 \cdot 9\end{array}$ & $\begin{array}{l}363 \cdot 0 \\
392 \cdot 9 \\
400 \cdot 2 \\
403 \cdot 1 \\
407 \cdot 1\end{array}$ & $\begin{array}{l}90 \cdot 4 \\
77 \cdot 0 \\
74 \cdot 9 \\
72 \cdot 4 \\
71 \cdot 4\end{array}$ \\
\hline $\begin{array}{l}\text { No. of } \\
\text { subjects }\end{array}$ & \multicolumn{2}{|c|}{2,169} & \multicolumn{2}{|c|}{722} \\
\hline
\end{tabular}

The increase from the third to the fifth reading was small, but significant in the case of males $(P<0.01)$

results from each subject's first attempt was relatively low, and the standard deviation was large. The mean for the second attempt was much higher, and there was still a slight increase from the third to the fifth measurement.

The regression coefficient, $b$, of mean peak 
expiratory flow (PEF) on height was calculated within separate age groups (Table II).

The variation of $b$ between age groups was not significant in either sex, so that the data can be represented by sets of parallel lines (Fig. 1) passing through the respective means for each age group $(, \bar{x}$ $\bar{y}$ in Table II) and having slopes equal to the

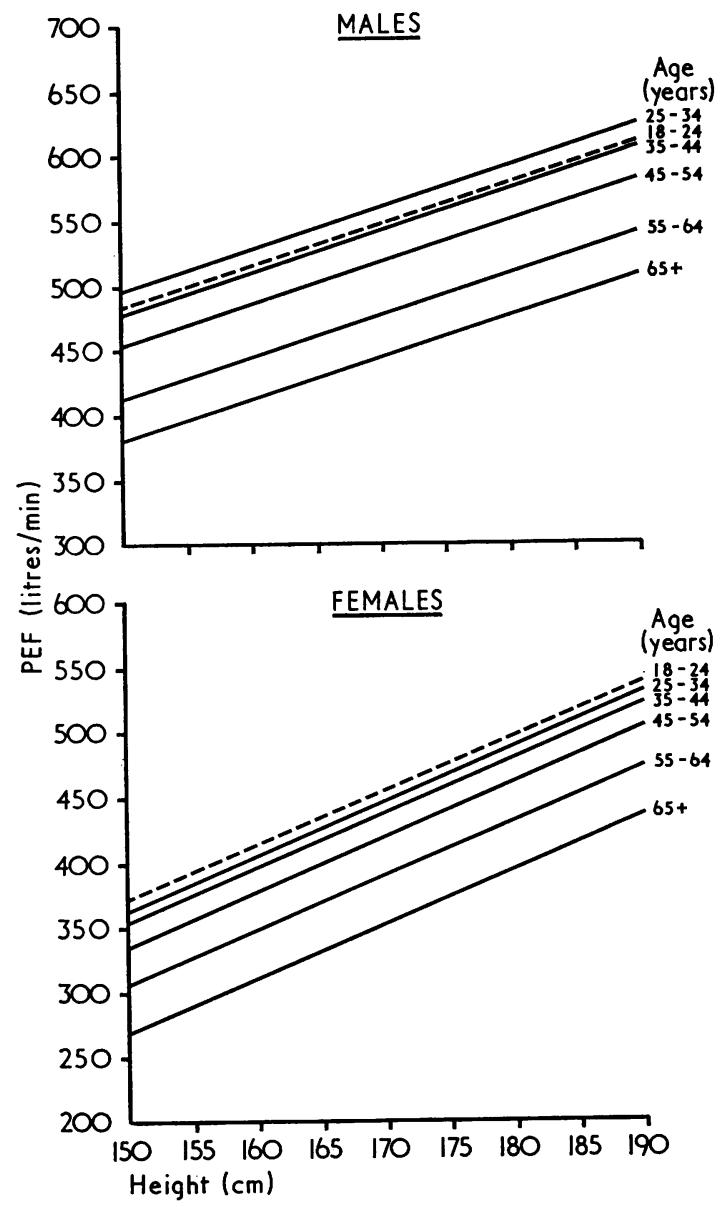

FIG. 1. Relationship between peak flow and height: the lines are drawn using the weighted mean slopes $(b)$ and mean heights and peak flows from Table II $(\bar{x}, \bar{y})$. Males, $y-\bar{y}=$ $3 \cdot 25(x-\bar{x})$. Females, $y-\bar{y}=4 \cdot 22(x-x)$.

weighted means of those in Table II. This model provided a very simple means of adjusting each individual's peak flow results to the equivalent values at standard heights, chosen as the mean values in the present series. The formulae used were (with PEF in $1 / \mathrm{min}$ and height in $\mathrm{cm}$ ): $M$ Height standardized $\mathrm{PEF}=$

Observed PEF-3.25 (Height-174)
T A B LE I I

MEAN HEIGHTS AND PEF BY AGE, WITH REGRESSION COEFFICIENT OF PEF ON HEIGHT

\begin{tabular}{|c|c|c|c|c|}
\hline $\begin{array}{c}\text { Age } \\
\text { Range }\end{array}$ & $\begin{array}{l}\text { No. of } \\
\text { Subjects }\end{array}$ & $\begin{array}{c}\text { Mean } \\
\text { Height } \\
(\mathrm{cm})(\overline{\mathrm{x}})\end{array}$ & $\underset{(1 / \mathrm{min})(\dot{y})}{\text { Mean }}$ & $\begin{array}{l}\text { Regression } \\
\text { Coefficient } \\
\text { (b) and s.E. }\end{array}$ \\
\hline $\begin{array}{c}\text { Males } \\
18-24 \\
25-34 \\
35-44 \\
45-54 \\
55-64 \\
65+\end{array}$ & $\begin{array}{r}589 \\
524 \\
364 \\
308 \\
207 \\
42\end{array}$ & $\begin{array}{l}174 \cdot 6 \\
176 \cdot 0 \\
174 \cdot 4 \\
172 \cdot 8 \\
171 \cdot 8 \\
171 \cdot 2\end{array}$ & $\begin{array}{l}560 \\
578 \\
556 \\
526 \\
483 \\
447\end{array}$ & $\begin{array}{l}3 \cdot 19 \pm 0.42 \\
3 \cdot 01 \pm 0.46 \\
3.32 \pm 0.54 \\
3 \cdot 10 \pm 0.65 \\
3.96 \pm 0.85 \\
4.08 \pm 1.73\end{array}$ \\
\hline $\begin{array}{c}\text { Females } \\
18-24 \\
25-34 \\
35-44 \\
45-54 \\
55-64 \\
65+\end{array}$ & $\begin{array}{r}278 \\
119 \\
88 \\
96 \\
73 \\
15\end{array}$ & $\begin{array}{l}162 \cdot 4 \\
163 \cdot 5 \\
162 \cdot 6 \\
162 \cdot 2 \\
161 \cdot 6 \\
160 \cdot 1\end{array}$ & $\begin{array}{l}423 \\
419 \\
406 \\
385 \\
353 \\
311\end{array}$ & $\begin{array}{l}4.08 \pm 0.49 \\
3.85 \pm 0.75 \\
5.37 \pm 1.11 \\
3.73 \pm 1.11 \\
4.57 \pm 0.99 \\
4.83 \pm 3.03\end{array}$ \\
\hline
\end{tabular}

Subjects under 18 were omitted from this analysis.

$F$ Height standardized $\mathrm{PEF}=$

Observed PEF-4.22 (Height-162)

The difference in the regression coefficients for males and females was not significant, but since different standard heights were required for the two sexes, it was considered appropriate to keep the regression coefficients separate too.

To demonstrate the variation of heightstandardized peak flow with age, mean values for five-year age ranges are plotted in Fig. 2, which shows that there are maxima in the twenties and a gradual decline with further increase in age.

In a separate study (Waller and Brooks, 1972), height-standardized weights were calculated for the men in this study, and these have been used to examine the relationship between peak flow and weight. The results showed that while the regression coefficients of peak flow on weight were significant in several age groups, they were small compared with those of peak flow on height, and there was no advantage in standardizing for weight also.

SMOKING At all ages over 20 about $40 \%$ of the men smoked (Table III) compared with $57 \%$ of clerical workers in the general population in 1968 (Todd, 1969). The proportion of women who smoked was close to $30 \%$ over most of the age range. There has been a general decline in smoking among professional and clerical workers in recent years (Royal College of Physicians, 1971) but even so the proportion of smokers in this sample was somewhat lower than expected from the general population figures.

Among men, smoking appeared to have little effect on peak flow but among women there was a steady decline with the amount smoked (Table IV). In each sex the highest mean peak flows were 
for ex-smokers or light cigarette smokers, and there was some evidence that the means for nonsmokers were reduced by the inclusion of subjects with symptoms of asthma who had avoided smoking for that reason. Table IV therefore gives a biased impression, and some other indication of the effects of smoking was sought in the data. For men the sample was large enough to follow the trend in peak flow with age separately for smokers and non-smokers (Fig. 3).

Up to age 45 there was no consistent difference between smokers and non-smokers, but after that the mean values for smokers were lower. The number of subjects within each group was small and the individual differences between means were

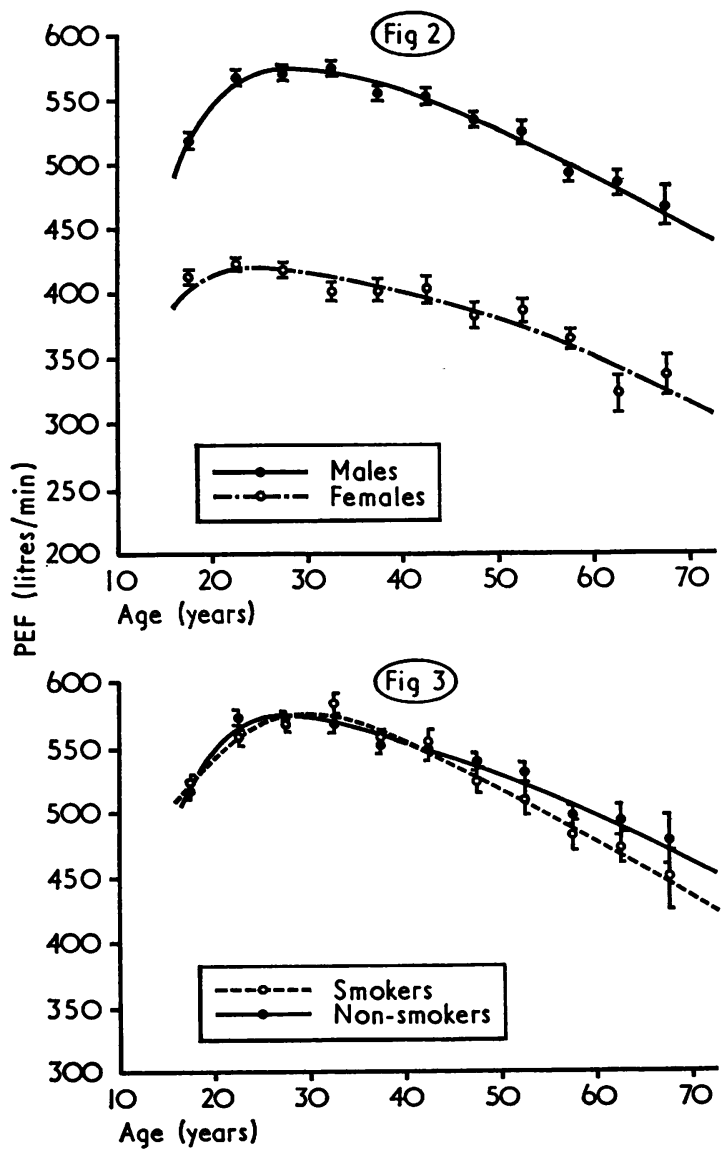

FIG. 2. Variation in peak flow with age, based on results standardized for heights of $174 \mathrm{~cm}(M)$ and $162 \mathrm{~cm}(F)$. Points indicate mean \pm S.E.

FIG. 3. Variation in peak flow with age, for smokers and non-smokers (including ex-smokers), males only, standard height of $174 \mathrm{~cm}$. Points indicate mean \pm S.E.
T A B L E I I I

PERCENTAGE OF SMOKERS IN THE SURVEY POPULATION

\begin{tabular}{|c|c|c|c|c|c|c|c|}
\hline & & \multicolumn{6}{|c|}{ Age Range } \\
\hline & & $15-$ & $20-$ & $35-$ & $45-$ & $55-$ & $65+$ \\
\hline $\begin{array}{l}\text { Males } \\
\text { Non-smokers } \\
\text { Ex-smokers } \\
\text { Smokers .. }\end{array}$ & $\begin{array}{l}\cdots \\
\cdots\end{array}$ & $\begin{array}{r}41 \\
7 \\
52\end{array}$ & $\begin{array}{l}43 \\
14 \\
43\end{array}$ & $\begin{array}{l}43 \\
21 \\
36\end{array}$ & $\begin{array}{l}28 \\
33 \\
39\end{array}$ & $\begin{array}{l}27 \\
26 \\
47\end{array}$ & $\begin{array}{l}31 \\
29 \\
40\end{array}$ \\
\hline $\begin{array}{l}\text { Females } \\
\text { Non-smokers } \\
\text { Ex-smokers } \\
\text { Smokers .. }\end{array}$ & $\ddot{x}$ & $\begin{array}{r}56 \\
7 \\
37\end{array}$ & $\begin{array}{l}57 \\
10 \\
33\end{array}$ & $\begin{array}{l}48 \\
15 \\
37\end{array}$ & $\begin{array}{l}53 \\
19 \\
28\end{array}$ & $\begin{array}{l}50 \\
19 \\
31\end{array}$ & $\begin{array}{l}73 \\
14 \\
13\end{array}$ \\
\hline
\end{tabular}

not significant, but the curves appeared to diverge at the older ages, suggesting that the peak flows of smokers declined more rapidly than did those of the men who had never smoked or who had given up. A separate regression analysis of the data over the age range 35 to 75 indicated a decline of $35 \mathrm{l} / \mathrm{min}$ per decade for people who continued to smoke and $29 \mathrm{l} / \mathrm{min}$ per decade for others, but the difference in slopes was not significant.

T A B L E I V

MEAN PEAK FLOW IN RELATION TO SMOKING HABITS

\begin{tabular}{|c|c|c|c|c|}
\hline \multirow{3}{*}{ Smoking Category } & \multicolumn{4}{|c|}{ PEF (1/min) } \\
\hline & \multicolumn{2}{|c|}{ Males } & \multicolumn{2}{|c|}{ Females } \\
\hline & No. & Mean \& S.E. & No. & Mean \& S.E. \\
\hline $\begin{array}{l}\text { Non-smokers } \\
\text { Pipe/cigar smokers } \\
\text { Ex-cigarette smokers } \\
\text { Cigarette smokers: }\end{array}$ & $\begin{array}{l}845 \\
158 \\
373\end{array}$ & $\begin{array}{l}547( \pm 3) \\
546( \pm 7) \\
549( \pm 5)\end{array}$ & $\frac{397}{83}$ & $\begin{array}{l}399( \pm 3) \\
414( \pm 8)\end{array}$ \\
\hline $\begin{array}{c}1-4 \text { /day } \\
5-14 \\
15-24 \\
25+\end{array}$ & $\begin{array}{r}83 \\
261 \\
334 \\
79\end{array}$ & $\begin{array}{l}549( \pm 8) \\
540( \pm 5) \\
539( \pm 4) \\
539( \pm 9)\end{array}$ & $\begin{array}{l}38 \\
95 \\
75 \\
25\end{array}$ & $\begin{array}{l}415( \pm 10) \\
407( \pm 6) \\
392( \pm 7) \\
363( \pm 12)\end{array}$ \\
\hline
\end{tabular}

These figures are standardized for height and age.

ENVIRONMENTAL FACTORS We were interested in the possible effect of exposure to air pollution on peak flow within this group. Most subjects spent their working day in the small area of the City (the commercial centre of London) where concentrations of smoke are now very low by normal urban standards in the United Kingdom and those of sulphur dioxide are by the same standard rather high. All of them, therefore, suffered much the same exposure to air pollution at work, but we were able to calculate separate mean peak flows for subjects whose homes were anywhere within the Greater London area and others, most of whom lived in semi-rural suburbs. We also separated the peak flow results by place of birth, for there is evidence that exposure to pollution in early childhood has a lasting effect on respiratory disease (Douglas and Waller, 1966) and pollution by smoke has been declining in London since the early part of the century. 
Initially, mean height-standardized peak flow was tabulated in relation to area of birth and residence for all ages combined (Table V), standardizing also for the substantial differences in age distribution between the four sub-groups from the internal data of this study.

\section{T A B L E V}

MEAN PEAK FLOW IN RELATION TO PLACE OF BIRTH AND RESIDENCE

\begin{tabular}{c|c|c|c|c|c}
\hline & & \multicolumn{4}{|c}{ PEF (1/min) } \\
\cline { 3 - 6 } $\begin{array}{c}\text { Place of } \\
\text { Birth }\end{array}$ & $\begin{array}{c}\text { Present } \\
\text { Residence }\end{array}$ & \multicolumn{2}{|c|}{ Males } & \multicolumn{2}{|c}{ Females } \\
\cline { 3 - 6 } & & No. & Mean \& S.E. & No. & Mean \& S.E. \\
\hline $\begin{array}{c}\text { Greater } \\
\text { London }\end{array}$ & $\begin{array}{c}\text { Outside } \\
\text { G.L. }\end{array}$ & 272 & $535( \pm 5)$ & 67 & $396( \pm 7)$ \\
$\begin{array}{c}\text { Greater } \\
\text { London }\end{array}$ & $\begin{array}{c}\text { Greater } \\
\text { London }\end{array}$ & 824 & $542( \pm 3)$ & 316 & $402( \pm 4)$ \\
$\begin{array}{c}\text { Outside } \\
\text { G.L. }\end{array}$ & $\begin{array}{c}\text { Greater } \\
\text { London } \\
\text { Outside } \\
\text { G.L. }\end{array}$ & 473 & $544( \pm 4)$ & 171 & $403( \pm 5)$ \\
\hline
\end{tabular}

These figures are standardized for height and age. Subjects born or normally resident abroad are excluded from this analysis.

Differences in mean peak flow between groups were small, but they were consistent for men and women, and the lowest means were for people born in Greater London who had subsequently moved outside the area. The tendency for the mean peak flows of London-born subjects to be lower than those of subjects born elsewhere remained when this analysis was repeated within separate age groups, but with small numbers the differences were not in general significant.

The results were also analysed by month of birth, separately for all males and all females in the survey, to seek any evidence of effects related to exposure to adverse seasonal factors (high pollution, cold weather or infections) during early infancy. There were only small random variations in mean peak flow for each month of birth, and there was no evidence of any seasonal pattern.

\section{DISCUSSION}

The study reported here was done primarily as a demonstration within the public health exhibition, to illustrate some aspects of work in progress on the effects of environmental factors on health. The questions and measurements were kept as simple as possible and the demonstration was certainly effective in stimulating public interest. The exhibition was entitled 'Good Health' which may have attracted a section of the population that was particularly health conscious, but there was little evidence of this, and most of the subjects came into the permanent exhibition hall merely as a diversion in the lunch-hour.
One finding of interest is that peak flow is still increasing slightly with age around 20 , and changes little in early adult life. This agrees with the results to date in a separate study in which a small cohort is being followed through life from age 19 (Lawther, Brooks, and Waller, 1970). Few other series include subjects as young as 20 , and in that of Leiner et al. (1963), which forms the basis of 'normal' values for men quoted by Cotes (1968), the extrapolation back to age 20 of the steady decline seen at higher ages leads to predicted values for young adults that now appear to be too high. At higher ages our results for men come between those of the carefully screened 'healthy' population of $\mathrm{O}$ Leiner et al. (1963) and those of the more recent general population sample of Ferris et al. (1971). The maximum peak flow in men appears from our results (Fig. 2) to be reached at about age 28 , virtually the same as the figure of 27.6 years found by Stebbings (1971) from his sample in the United States.

Weight is not a useful predictor of peak flow since it confounds two opposing effects-muscular development, associated with an increase in peak flow, and obesity, associated with a decrease in peak flow. Many of the very high and very low readings were from subjects who were above average weight. In their survey in Sweden, Kallqvist, Taube, and Olafsson (1970) likewise found that while height was a good predictor of peak flow, weight gave inconclusive results, and they considered that this was due to a lack of discrimination between muscle and fat. Other anthropometric measurements may be more useful: Stebbings (1971) concluded that the relationship between pulmonary function and measurements such as handgrip strength needed re-investigation, and Ferris and Stoudt (1971) found that peak flow was more closely correlated with handgrip strength than with other measures.

Although differences in peak flow between smokers and non-smokers were not significant, the results suggest that the peak flow of smokers declines a little faster with age than that of nonsmokers. One problem in the interpretation of studies of this type is that populations of smokers and non-smokers are self-selected and the slightly more favourable results for light smokers and exsmokers may be a reflection of their being fit enough to smoke, whereas some of the nonsmokers were not. Questions on respiratory symptoms and clinical histories were not included in this study, but any information collected during the course of the brief interview was noted, and it was found that many of the subjects whose peak flow was well below the expected value reported 
histories of asthma and were non-smokers. Other authors have reported that people with symptoms of allergic asthma are less likely than others to smoke, and it has been suggested (Ford, 1971) that this may be the reason for their low incidence of lung cancer. Any initial 'advantage' that smokers have in terms of peak flow appears to be lost, however, by age 45 , after which mean values gradually fall below those of non-smokers. Similar findings have been reported in respect of other measures of ventilatory capacity: in the studies of Ferris, Anderson, and Zickmantel (1965) in the United States, and Ashford, Brown, Morgan, and Rae, (1968) in the United Kingdom, smokers were found to have slightly higher values of $\mathrm{FEV}_{1}$ than non-smokers in the younger age groups but a steeper decline with age.

There was no strong evidence from our results of any effect of exposure to air pollution on peak flow within this group. Holland, Halil, Bennett, and Elliott (1969), in a study carried out among schoolchildren living in different parts of Kent, found significant differences in peak flow according to the area of residence, and they considered that exposure to air pollution may have been responsible. In our case, variations in peak flow in relation to area of birth and residence were small, but most of the subjects were exposed during each working day to the general pollution levels of the City, so that the overall contrasts in exposure to air pollution were small. The relatively low values for London-born subjects who now live outside the metropolis may be the result of a selective movement of people with respiratory abnormalities from London to the 'cleaner' areas beyond.

While the peak flow meter is convenient for use in large surveys, the results of several recent papers suggest that it may be a poor indicator of early changes in airway resistance. Allen and Sabin (1971) compared the results of a wide range of spirometric measurements with those of direct measurements of conductance and found that indices based on the middle part of the expiratory curve correlated better with conductance and showed a greater change in relation to smoking than those based on the first part only. Also, in a study of the effects of cigarette smoking on teenagers, Seely, Zuskin, and Bouhuys (1971) found that while there was little difference in flow at the beginning of expiration, the smokers had lower flow rates at mid-vital-capacity than the nonsmokers. Since the peak flow meter measures flow only at the very beginning of expiration, it would not reflect changes of this type, which Seely et al. (1971) attribute to obstruction of the small airways. The absence of any distinction in peak flow between young smokers and non-smokers in our study may then be due primarily to the insensitivity of the instrument to these small changes.

Although the peak flow meter does not appear to be very helpful in detecting changes in the initial stages of the development of respiratory disease, it is certainly of value in later stages. In the present study, carried out among an active working population, the majority of the subjects were 'healthy', but even so some of the peak flow measurements were well below normal: in these cases the subjects were given a note of their results and they were referred to their own doctors for further investigation.

We are indebted to the Corporation of the City of London for providing facilities for this study, and to Dr. W. G. Swann, Medical Officer of Health, Port and City of London, Dr. D. T. Jones, and other members of the staff of the Public Health Department for their encouragement and assistance. We also wish to acknowledge the help and encouragement of the Director of the Air Pollution Unit, Professor P. J. Lawther. Other members of the staff of the Unit helped with the field work and gave valuable comments on the analysis of the results and the manuscript of this paper: much of the computer analysis was done by Mrs. Margaret Holmes.

\section{REFERENCES}

Allen, G. W., and Sabin, S. (1971). Comparison of direct and indirect measurement of airway resistance. A critical analysis of the forced vital capacity curve. Amer. Rev. resp. Dis., 104, 61.

Ashford, J. R., Brown, S., Morgan, D. C., and Rae, S. (1968). The pulmonary ventilatory function of coal miners in the United Kingdom. Amer. Rev. resp. Dis., 97, 810.

Cotes, J. E. (1968). Lung Function: Asses::nent and Application in Medicine, 2nd ed. Blackwell, Oxford.

Douglas, J. W. B., and Waller, R. E. (1966). Air pollution and respiratory infection in children. Brit. J. prev. soc. Med., $20,1$.

Ferris, B. G., Anderson, D. O., and Zickmantel, R. (1965). Predicted values for screening tests of pulmonary function. Amer. Rev. resp. Dis., 91, 252.

— Higgins, I. T. T., Higgins, M. W., Peters, J. M., Van Ganse, W. F., and Goldman, M. D. (1971). Chronic nonspecific respiratory disease, Berlin, New Hampshire, 1961-67: a cross-sectional study. Amer. Rev. resp. Dis., 104, 232.

- and Stoudt, H. W. (1971). Correlation of anthropometry and simple tests of pulmonary function. Arch. environm. Hlth, 22, 672.

Ford, R. M. (1971). Smoking, lung cancer, and asthma. Brit. med. J., 3, 372.

Holland, W. W., Halil, T., Bennett, A. E., and Elliott, A. (1969). Factors influencing the onset of chronic respiratory disease. Brit. med. J., 2, 205.

Kallqvist, I., Taube, A., and Olafsson, O. (1970). Peak expiratory flow in healthy persons aged 45-65 years. Scand. J. resp. Dis., 51, 177.

Lawther, P. J., Brooks, A. G. F., and Waller, R. E. (1970) Respiratory function measurements in a cohort of medical students. Thorax, 25, 172. 
Leiner, G. C., Abramowitz, S., Small, M. J., Stenby, V. B., and Lewis, W. A. (1963). Expiratory peak flow rate. Standard values for normal subjects. Use as a clinical test of ventilatory function. Amer. Rev. resp. Dis., 88, 644.

Medical Research Council (1966). Questionnaire on respiratory symptoms, 1966. Medical Research Council, London.

Royal College of Physicians (1971). Smoking and Health Now. Pitman, London.

Seely, J. E., Zuskin, E., and Bouhuys, A. (1971). Cigarette smoking: objective evidence for lung damage in teenagers. Science, 172, 741.
Stebbings, J. H. jun. (1971). Chronic respiratory disease among nonsmokers in Hagerstown, Maryland. II. Problems in the estimation of pulmonary function values in epidemiological surveys. Environ. Res., 4, 163.

Todd, G. F. (1969). Statistics of Smoking in the United Kingdom, 5th ed. Tobacco Research Council, London.

Waller, R. E., and Brooks, A. G. F. (1972). Heights and weights of men visiting a public health exhibition. Brit. J. prev. soc. Med., 26, 180.

Wright, B. M., and McKerrow, C. B. (1959). Maximum forced expiratory flow rate as a measure of ventilatory in capacity. Brit. med. J., 2, 1041. 